\title{
Letter \\ The future of mammary stem cell biology: the power of in vivo transplants
}

\author{
Geoffrey J Lindeman ${ }^{1}$, Jane E Visvader ${ }^{1}$, Matthew J Smalley² and Connie J Eaves ${ }^{3}$
}

1VBCRC Laboratory, The Walter and Eliza Hall Institute of Medical Research, 1G Royal Parade, Parkville, Victoria, Australia

${ }^{2}$ Breakthrough Toby Robins Breast Cancer Research Centre, The Institute of Cancer Research, Chester Beatty Laboratories, 237 Fulham Road, London, SW3 6JB, UK

${ }^{3}$ Terry Fox Laboratory, British Columbia Cancer Agency, 675 West 10th Avenue, Vancouver, British Columbia, V5Z 1L3, Canada

Corresponding author: Geoffrey J Lindeman, lindeman@wehi.edu.au

Published: 29 May 2008

Breast Cancer Research 2008, 10:402 (doi:10.1186/bcr1986)

This article is online at http://breast-cancer-research.com/content/10/3/402

(c) 2008 BioMed Central Ltd

See related review article by Smith and Medina, http://breast-cancer-research.com/content/10/1/203

The recent review by Smith and Medina [1] of in vivo transplantation models and their role in investigating mammary stem cell (MaSC) biology provides comprehensive coverage of the history and complexity of the 'gold standard' MaSC assay in mice. This includes a description of the pioneering studies that showed that mammary epithelial outgrowths can be generated in cleared mammary fat pads transplanted with explants or admixtures of mammary cells [2]. However, this approach clearly does not lend itself to prospective analysis of isolated subpopulations in order to identify which cells possess in vivo regenerative activity. More recently, success in obtaining complex mammary gland structures from transplanted suspensions of single cells has now made this possible [3-7]. Moreover, the regenerated structures have been shown to contain daughter cells with the same in vivo repopulating activity of the original stem cell transplanted $[4,6]$. A major contribution from this advance has been the demonstration that the MaSCs thus defined are highly enriched in the CD49fhi/CD29hi/CD24+/mod/Sca-1- subset [4-6]. Nevertheless, it is important to recognize that these stem cells represent under $10 \%$ of this basal population. This population also contains mature myoepithelial cells and, in all likelihood, other basal cell intermediates that are yet to be identified.

Smith and Medina [1] suggest that a conflict may exist in the consistency of CD49f, CD29 and CD24 as positive mouse MaSC markers. However, we find the results reported thus far to be in full agreement with one another. The CD49fhi/ CD24 ${ }^{\text {med }}$ population described by Stingl and coworkers [6] is identical to the CD29hi/CD24+ population described by Shackleton and colleagues [4] and to the CD49fhi/CD24lo/ Sca-1- population reported by Sleeman and coworkers [5].
Specifically, there is considerable overlap (>85\%) between the fraction of $\mathrm{CD}_{24}{ }^{+}$cells that are CD49fhi and CD29hi, suggesting that $\alpha_{6}$ and $\beta_{1}$ integrin (CD49f and CD29, respectively) are co-expressed in the basal stem cell-enriched population (unpublished data). Although the MaSC-enriched population is $\mathrm{CD}^{2} 4^{+}$, the level of expression is clearly lower than in cells with luminal features, including luminal progenitors $[5,6]$. Different levels of fluorescence are obtained with different anti-CD24 reagents and staining protocols, and this has led to differential reporting of MaSCs as CD24+, CD24 ${ }^{\mathrm{mod}}$, or CD24lo [8]. The resultant confusion is unfortunate and underscores the need for improved standardization in phenotyping procedures and nomenclature.

There is also consistency in the reported phenotypes of luminal progenitors and their more mature progeny. The latter are widely recognized to be CD24+hi/CD29lo/CD61\% prominin $-1^{+} / \mathrm{Sca}-1^{+}$, whereas the luminal progenitors are CD24+/hi/CD29lo/CD61+/prominin-1 . The CD24hi/prominin1\% Sca-1 population described by Sleeman and coworkers [8] contains within it the CD29/o/CD24+/CD61+ population isolated by Asselin-Labat and coworkers [9] (Smalley MJ, unpublished data). This accounts for our similar observations of oestrogen receptor- $\alpha$ expression being largely confined to the more mature CD24+/hi/CD61\%/prominin-1+/Sca-1+ luminal cells (although a potentially important finding is that a small fraction of luminal progenitor cells also express ER- $\alpha$ ) [8-10].

Smith and Medina [1] rightly highlight the combinatorial interactions between various epithelial cells and the mammary fat pad stroma that occur during the formation of a complete mammary gland. At a single cell level, the MaSC clearly must undergo asymmetric divisions in the stroma to yield progeny

MaSC $=$ mammary stem cell. 
that ultimately generate a complete bilayered mammary tree. However, they also suggest that undue emphasis on the isolation of MaSCs is deflecting attention from more fundamental issues of the nature of the cellular interactions that must take place. Although we share their interest and perceived importance of these issues, we believe continuing efforts to purify and more precisely characterize the various cell types involved in these processes will provide an essential complementary approach. The separation of mammary epithelial subpopulations, through the identification of biologically distinct stem, progenitor and mature cell types, has the unique power to provide a clear framework for investigations of how different types of cells within the mammary gland normally communicate with each other and their environment and which of these can be bona fide targets of oncogenic transformation.

Delineating the molecular signals and their collective roles in regulating normal MaSC behaviour as well as how these may be disrupted to produce malignant breast cancer populations holds significant challenges for the future. The use of cell purification and characterization studies has proven a highly insightful strategy in the haematopoietic system and has led to the identification of clinically useful diagnostic markers and therapies. Taking a lead from this experience, we anticipate that a continuing focus on the isolation of functionally distinct mammary epithelial populations from both murine and human sources at increasing purities, if developed critically, will play an important role in enabling similar progress in the mammary field.

\section{Competing interests}

The authors declare that they have no competing interests.

\section{References}

1. Smith GH, Medina D: Re-evaluation of mammary stem cell biology based on in vivo transplantation. Breast Cancer Res 2008, 10:203.

2. Daniel CW, De Ome KB, Young JT, Blair PB, Faulkin $L J$ Jr: The in vivo life span of normal and preneoplastic mouse mammary glands: a serial transplantation study. Proc Natl Acad Sci USA 1968, 61:53-60.

3. Alvi AJ, Clayton $\mathrm{H}$, Joshi $\mathrm{C}$, Enver $\mathrm{T}$, Ashworth $\mathrm{A}$, Vivanco MM, Dale TC, Smalley MJ: Functional and molecular characterisation of mammary side population cells. Breast Cancer Res 2003, 5:R1-R8

4. Shackleton M, Vaillant F, Simpson KJ, Stingl J, Smyth GK, AsselinLabat ML, Wu L, Lindeman GJ, Visvader JE: Generation of a functional mammary gland from a single stem cell. Nature 2006, 439:84-88.

5. Sleeman KE, Kendrick $H$, Ashworth A, Isacke CM, Smalley MJ: CD24 staining of mouse mammary gland cells defines luminal epithelial, myoepithelial/basal and non-epithelial cells. Breast Cancer Res 2006, 8:R7.

6. Stingl J, Eirew P, Ricketson I, Shackleton M, Vaillant F, Choi D, Li $\mathrm{HI}$, Eaves CJ: Purification and unique properties of mammary epithelial stem cells. Nature 2006, 439:993-997.

7. Welm BE, Tepera SB, Venezia T, Graubert TA, Rosen JM, Goodell MA: Sca-1(pos) cells in the mouse mammary gland represent an enriched progenitor cell population. Dev Biol 2002, 245:42-56.

8. Sleeman KE, Kendrick H, Robertson D, Isacke CM, Ashworth A, Smalley MJ: Dissociation of estrogen receptor expression and in vivo stem cell activity in the mammary gland. $J$ Cell Biol
2007, 176:19-26

9. Asselin-Labat ML, Sutherland KD, Barker H, Thomas R, Shackleton M, Forrest NC, Hartley L, Robb L, Grosveld FG, van der Wees J, Lindeman GJ, Visvader JE: Gata-3 is an essential regulator of mammary-gland morphogenesis and luminal-cell differentiation. Nat Cell Biol 2007, 9:201-209.

10. Asselin-Labat ML, Shackleton M, Stingl J, Vaillant F, Forrest NC, Eaves CJ, Visvader JE, Lindeman GJ: Steroid hormone receptor status of mouse mammary stem cells. J Natl Cancer Inst 2006, 98:1011-1014. 